\title{
O papel da literatura na escola
}

Regina ZiLberman

UFRGS - FAPA

RESUMO: ESTE TEXTO PRETENDE DISCUTIR ALGUMAS QUESTÕES SOBRE A LEITURA LITERÁRIA E O PAPEL DA LITERATURA NA ESCOLA, SEUS PRESSUPOSTOS HISTÓRICOS E TEÓRICOS E O PRAGMATISMO DAS ATIVIDADES PEDAGÓGICAS ENVOLVIDOS NESSA ESPECIFICIDADE DE LEITURA.

ABSTRACT: THIS PAPER WILL DISCUSS SOME QUESTIONS ABOUT THE LITERARY READING AND THE ROLE OF LITERATURE IN SCHOOL, THEIR HISTORICAL AND THEORETICAL ASSUMPTIONS AND PRAGMATISM OF THE ACTIVITIES INVOLVED IN SPECIFIC TEACHING OF READING.

PALAVRAS-CHAVE: LEITURA - LITERATURA - ESCOLA - HISTÓRIA KEY-WORDS: READING - LITERATURE - SCHOOL - HISTORY 


\section{Pressupostos históricos e teóricos}

Pode-se situar na virada dos anos 70 para os anos 80 a data em que se intensificaram e expandiram as discussões relativas à leitura na escola e ao papel da literatura no ensino. O período caracterizava-se pela descompreensão do regime militar, na esteira das manifestações públicas de insatisfação com o modelo autoritário de governo e da falência do projeto desenvolvimentista abraçado pelo Estado. Entre o final da vigência do Ato Institucional número 5, o AI-5, em 1979, e as primeiras exigências de eleições diretas para a presidência da república, em 1984, o país dá os primeiros passos na direção da redemocratização.

É neste contexto que se verifica um movimento amplo, envolvendo sobretudo pesquisadores das áreas de Letras e Pedagogia, preocupados com os rumos da escola brasileira, a qualidade de ensino, a qualificação do professor e os resultados da aprendizagem, que, transcorrida uma década da reforma da educação brasileira, datada de 1970, se mostravam não apenas insuficientes, mas - e principalmente - alarmantes, já que o horizonte futuro prognosticava pioras, e não melhoramento ou superação dos problemas.

São sintomas desse movimento iniciativas como a realização do I Congresso de Leitura (COLE), em Campinas, em 1978, do I Encontro de Professores Universitários de Literatura Infantil e Juvenil, no Rio de Janeiro, em 1980, e a Primeira Jornada Sul-Rio-Grandense de Literatura, em 1981, em Passo Fundo, eventos que se mostraram frutíferos e duradouros. Por sua vez, vocacionada para a difusão e o fortalecimento da literatura infantil e juvenil brasileira, a Fundação Nacional do Livro Infantil e Juvenil patrocinava, desde 1974, ações comprometidas com a qualificação das obras dirigidas ao público infantil e com a interlocução entre essa produção e o trabalho do professor, preparando-o crítica e pedagogicamente para lidar, em sala de aula, com textos adequados aos alunos.

A emergência de associações, como a de Professores de Língua e Literatura (APLL) e de Leitura do Brasil (ALB), entre o final dos anos 70 e o começo dos anos 80 , é também sinal do engajamento de educadores e pesquisadores na discussão tanto dos problemas de ensino e aprendizagem no âmbito da escola, quanto das políticas públicas que poderiam alavancar uma ação simultaneamente democratizadora e competente que beneficiasse docentes e discentes. Uma agenda positiva mobilizava sobretudo intelectuais atuantes na 
universidade, originários, como se observou, dos campos da Pedagogia e das Letras, fecundando, por sua vez, pesquisas em áreas adjacentes, como História e Artes, ou não tão próximas, como Ciências e Matemática, em razão de sua presença, enquanto disciplinas, nos currículos de ensino fundamental.

No âmbito dessas discussões, que envolvia a aprendizagem e o uso da língua portuguesa, recebeu a literatura uma valorização específica, pois era nela que se colocavam as esperanças de superação dos problemas experimentados na sala de aula. Com efeito, se os diagnósticos identificavam as dificuldades de leitura e expressão escrita por parte dos estudantes, era à literatura, representada por obras de ficção e de poesia, que se transferiam os créditos e as expectativas de mudança e de sucesso quando do exercício da ação educativa por parte dos docentes.

A literatura encarnava a utopia de uma escola renovada e eficiente, de que resultavam a aprendizagem do aluno e a gratificação profissional do professor.

Quase três décadas depois, muita água rolou por debaixo da ponte: o Brasil se redemocratizou, o surto inflacionário, crescente na década de 80 do século XX, foi contido, uma nova Constituição passou a vigorar a partir de 1988, a economia globalizou-se, o ensino básico passou por outras e sucessivas reformas, algumas nominais (antes de chamar-se ensino básico, foi designado sucessivamente ensino fundamental e secundário, e ensino de primeiro e segundo graus, por exemplo) e outras estruturais, estabeleceram-se parâmetros curriculares e, após a virada do milênio, o sistema de cotas passou a vigorar em muitas universidades públicas, tornando-se obrigatório.

A cultura experimentou igualmente alterações substantivas: os meios de comunicação de massa expandiram-se de modo notável do ponto de vista tecnológico e instrumental, e introduziram-se novos suportes, como o eletrônico e o digital, e dispositivos revolucionários, como o computador pessoal e o telefone celular. Comparados os meios de veiculação de textos utilizados no começo dos anos 1980 com os disponíveis ao final da primeira década do nosso milênio, a distância parece gigantesca, embora menos de trinta medeie um tempo e outro. $\mathrm{Na}$ passagem dos anos 70 para os 80 , o livro apresentavase como o receptáculo soberano e insofismável do texto, crença hoje descartada mesmo por aqueles que entendem o impresso como constituindo ainda o formato mais adequado para receber e perenizar a escrita, em decorrência de seu baixo custo e facilidades de manuseio e de circulação. 
Outras mudanças fizeram-se igualmente notar no Brasil do século XXI: a globalização e o neoliberalismo impuseram novas formas de financiamento da cultura, visto que o Estado, em muitas ocasiões, deixa-a ao desamparo. Por outro lado, obsolesceram críticas, como as emanadas dos pensadores associados à Escola de Frankfurt, condenando a indústria cultural e seus subprodutos, como os best-sellers, as histórias em quadrinho, a novela de televisão, ou as manifestações populares, como o cordel, o funk, o rap e o hip hop, expressões muitas vezes anônimas, como o causo, no meio rural, o grafite, no cenário urbano, e a fanfiction, no ambiente digital.

O aparecimento dos Estudos Culturais e a sua consolidação na universidade sinalizam não apenas o novo olhar posto sobre a cultura, mas as modificações por que essa passou no trânsito do século XX para o XXI. A ruptura das fronteiras entre o centro e a periferia, o erudito e o popular, entre a "alta literatura" e o pop, entre o clássico e o fashion, o rural e o urbano, determinou certa euforia que vigora nos meios tanto acadêmicos, quanto artísticos. A constatação de que tudo é cultura, e de que tudo é válido, alarga as potencialidades de criação e de investigação, de que resulta o bem-estar reinante nos segmentos focados nas expressões da arte e do pensamento.

Tudo o que mudou parece ter mudado para melhor - menos a escola, com suas conseqüências: a aprendizagem dos alunos, a situação do professor, as políticas públicas dirigidas à educação, para não se mencionarem as condições de trabalho, onde predomina a insegurança, e o espaço físico das salas de aula, degradado e degradante. Onde deveria reinar a mesma euforia, predominam a desolação, o desestímulo, os sentimentos de decepção e de fracasso.

Com efeito, os problemas educacionais permanecem, tendo-se somado novas razões às antigas queixas. O empobrecimento da escola pública é visível em todo o país, ampliando-se a clivagem entre as instituições de ensino destinadas às classes pobres, localizadas na periferia urbana, e as que atendem as camadas superiores. A depauperação dos professores, submetidos a maus salários e ao desdém por parte do poder público, se evidencia em ambas as circunstâncias. Contudo, recaem sobre o professor e sobre o sistema escolar as maiores cobranças, seja por os velhos problemas persistirem, de que resultam performances negativas em avaliações contínuas (PISA, SAEB, entre outros), seja por não saberem se posicionar perante os novos desafios, os que são colocados pelas mudanças tecnológicas e científicas, que seguidamente 
monopolizam as preferências dos jovens, e os que dizem respeito à situação vivida, em nossos dias, pela mocidade, vítima e sujeito da violência urbana, rotineira no cotidiano nacional.

Os professores, na qualidade de profissionais da educação, poderiam apelar para os versos de Drummond: "Teus ombros suportam o mundo" (ANDRADE, 2002: 80). No entanto, seguidamente, se questionam sobre a natureza de seu ofício, ao interrogarem a si e a seus colegas sobre o que deve a escola oferecer. Relativamente à leitura, que ocupa a base do ensino e da qual se espera tanto, a pergunta talvez seja: que tipo de leitura caberia à escola estimular?

Por muito tempo a resposta foi facilmente enunciável, já que, como a escola destinava-se sobretudo às elites, tratava-se de difundir a língua padrão e a literatura canônica, com a qual se identificavam os freqüentadores das salas de aula. Quando se expandiu a escola brasileira, na esteira do processo de modernização da sociedade, associada à industrialização, à migração do campo para a cidade e ao crescimento da população urbana, aquela resposta mostrou-se insuficiente. Os novos contingentes não se identificaram com a norma culta e desconheciam a tradição literária, a quem cabia apresentar, talvez pela primeira vez.

Da alfabetização, tarefa que a escola desempenhou burocraticamente desde seus inícios, passou-se à necessidade de letramento, sobretudo de letramento literário. A leitura de textos apresenta-se como prática inusitada, e a literatura, em boa parte das escolas nacionais, como um alienígena, sobretudo nas que atendem os segmentos populares, mesmo em grandes centros urbanos.

É igualmente sob esse prisma que se pode entender porque os "ombros" do professor "suportam o mundo", visto que são atribuídas a ele várias e distintas missões: alfabetizar, facultar o domínio, pelo aluno, do código escrito, formar leitores qualificados de textos literários. Talvez por serem muitas as tarefas e as condições de trabalho provavelmente precárias, escola e professores raras vezes alcançam qualquer um desses resultados, a se acreditar nos testes a que são submetidos os estudantes, quando se revelam pouco aptos aos tipos de leitura indicados.

Diante disso, novas questões se evidenciam: como formar leitores competentes de textos escritos informativos e, simultaneamente, bons apreciadores de literatura? Ou é preferível optar por preparar leitores em, ao menos, uma dessas modalidades, esperando que, por decorrência, o resultado conduza o aluno a outros tipos de texto? Drummond também aqui dá a letra, quando escreve: 
Visito os fatos, não te encontro.

Onde te ocultas, precária síntese, penhor de meu sono, luz dormindo acesa da varanda?

(ANDRADE, 2002: 126)

Como se observou, nos anos 80 , as fichas eram colocadas na leitura da literatura, aposta que ainda compartilhamos, embora tenhamos necessariamente de reconhecer as mudanças ocorridas e as novas necessidades apresentadas. Para tanto, não podemos deixar de ter presente o que a literatura oferece a seu leitor, incluído nesse processo o que representa o ato de ler.

Assim, não se trata de rejeitar o caminho percorrido, mas de ajustá-lo aos novos tempos, pois a história não pára. Trata-se, por outro lado, de reiterar premissas e pressupostos, para que se atinjam as metas desejadas, constando entre elas a melhoria das condições de ensino, por meio do alcance de resultados positivos em sala de aula, a valorização do professor e a progressiva democratização do saber na sociedade brasileira contemporânea.

\section{A leitura da literatura}

A literatura introduziu-se na escola desde o começo da história dessa instituição. Testemunhos dão conta que, entre os sumérios, povo a que se atribui a invenção da escrita, já se estabelecera a prática de transmissão de textos canônicos por intermédio de uma entidade administrada, no caso daquela coletividade, por sacerdotes (Cf. EVEN-ZOHAR, 1999: 29). Contudo, o modelo de escola que ainda subsiste é herança dos gregos dos séculos V e IV a.C., que conferiram à poesia e à prosa a função de transmitir um padrão lingüístico e um patrimônio cultural aos jovens atendidos pelo grammatistes, nome pelo qual eram conhecidos os professores (Cf. KENNEDY, 1994: 82-83).

Atualmente não mais compete ao ensino da literatura a transmissão de um patrimônio já constituído e consagrado, mas a responsabilidade pela formação do leitor. Por sua vez, a execução dessa tarefa depende de se conceber a leitura não como o resultado satisfatório do processo de letramento e decodificação de matéria escrita, mas como atividade propiciadora de uma experi- 
ência única com o texto literário. A literatura se associa então à leitura, do que advém a validade dessa.

A experiência da leitura decorre das propriedades da literatura enquanto forma de expressão, que, utilizando-se da linguagem verbal, incorpora a particularidade dessa de construir um mundo coerente e compreensível, logo, racional. Esse universo, da sua parte, alimenta-se da fantasia do autor, que elabora suas imagens interiores para se comunicar com o leitor. Assim, o texto concilia a racionalidade da linguagem, de que é testemunha sua estrutura gramatical, com a invenção nascida na intimidade de um indivíduo; e pode lidar com a ficção mais exacerbada, sem perder o contato com a realidade, pois precisa condicionar a imaginação à ordem sintática da língua. Por isso, a literatura não deixa de ser realista, documentando seu tempo de modo lúcido e crítico; mas revela-se sempre original, não esgotando as possibilidades de criar, pois o imaginário empurra o artista à geração de formas e expressões inusitadas.

Dúbia, a literatura provoca no leitor um efeito duplo: aciona sua fantasia, colocando frente a frente dois imaginários e dois tipos de vivência interior; mas suscita um posicionamento intelectual, uma vez que o mundo representado no texto, mesmo afastado no tempo ou diferenciado enquanto invenção, produz uma modalidade de reconhecimento em quem lê. Nesse sentido, o texto literário introduz um universo que, por mais distanciado da rotina, leva o leitor a refletir sobre seu cotidiano e a incorporar novas experiências (cf. ISER, 1993).

A leitura do texto literário constitui uma atividade sintetizadora, permitindo ao indivíduo penetrar o âmbito da alteridade sem perder de vista sua subjetividade e história. O leitor não esquece suas próprias dimensões, mas expande as fronteiras do conhecido, que absorve através da imaginação e decifra por meio do intelecto. Por isso, trata-se também de uma atividade bastante completa, raramente substituída por outra, mesmo as de ordem existencial. Essas têm seu sentido aumentado, quando contrapostas às vivências transmitidas pelo texto, de modo que o leitor tende a se enriquecer graças ao seu consumo.

Se esse é o ângulo individual da leitura, o ângulo social decorre dos efeitos desencadeados. O leitor tende a socializar a experiência, cotejar as conclusões com as de outros leitores, discutir preferências. A leitura estimula o diálogo, por meio do qual se trocam resultados e confrontam-se gostos. Portanto, não se trata de uma atividade egocêntrica ou narcisista, se bem que, no começo, 
exercida solitariamente; depois, aproxima as pessoas e coloca-as em situação de igualdade, pois todos estão capacitados a ela.

Em certa medida, a leitura sugere outra faceta educativa da literatura: o texto artístico talvez não ensine nada, nem queira fazê-lo; mas seu consumo induz a práticas socializantes, que, estimuladas, mostram-se democráticas, porque igualitárias.

O exercício da leitura é o ponto de partida para a aproximação à literatura. A escola dificilmente o promoveu, a não ser quando condicionado a outras tarefas, a maior parte de ordem pragmática. Hoje, quando o ensino está em crise, apresenta-se como necessidade prioritária, pois faculta avizinhar-se a um objeto tornado estranho no meio escolar. Porém, talvez se constitua também no ponto de chegada, na medida em que oferece opções diversas daquelas recorrentes na história da educação.

Estas alternativas talvez possam ser transpostas à própria escola que, atualmente, parece ter perdido a eficácia que um dia teve, substituída pela dos meios de comunicação de massa e da comunicação eletrônica. Sua sobrevivência enquanto instituição, portanto, depende de um posicionamento na vanguarda dos fatos históricos. Poderá fazê-lo, caso se solidarizar a seus usuários, servir-lhes de veículo para manifestação pessoal e colaborar para sua auto-afirmação. O exercício da leitura do texto literário em sala de aula pode preencher esses objetivos, conferindo à literatura outro sentido educativo, auxiliando o estudante a ter mais segurança relativamente às suas próprias experiências.

\section{A fantasia e a utopia da educação}

A leitura acontece quando a imaginação é convocada a trabalhar junto com o intelecto, responsável pelas operações de decodificação e entendimento de um texto ficcional. O resultado é a fruição da obra, sentimento de prazer motivado não apenas pelo arranjo convincente do mundo fictício proposto pelo escritor, mas também pelo estímulo dado ao imaginário do leitor, que assim navega em outras águas, diversas das familiares a que está habituado.

Definida enquanto criação, a obra literária não é produzida sem que outra imaginação seja ativada primeiro: a do escritor. Por isso, coincide com invenção, associa-se à fantasia, parece irreal. De um lado, simula lidar com coisas e pessoas 
conhecidas; de outro, porém, deixa claro que aquelas nunca tiveram existência concreta, tangível ou mensurável. Reais são apenas as palavras que as enunciam; essas, no entanto, também são impalpáveis. Onde então situar a materialidade da literatura, localizada, supõe-se, em algum lugar, já que nos atinge tanto?

A resposta a essa questão talvez seja tão imprecisa quanto o objeto a que ela se refere: tudo começa na fantasia, cuja existência pode ser confirmada de modo empírico, já que diariamente experimentamos seus efeitos, mas cujo cerne não tem substância, nem forma.

O que é a fantasia? Eis um tema negligenciado, quando a fantasia é considerada uma forma de alheamento do universo imediato experimentado e conhecido pelos seres humanos; ou mesmo rejeitado, por ser a fantasia julgada improdutiva pela sociedade capitalista, que não tolera uma atividade não rendosa e sem aplicação.

Uma perspectiva mais doutrinária a exilou, expulsando-a de seu universo conceitual e denegrindo seus efeitos; outra, mais pragmática, não a evitou, mas, ao adotá-la, comprometeu sua finalidade. Esta foi encampada pela indústria cultural, que lhe conferiu sentido escapista, encarregando-a, por uma parte, de proporcionar a fuga, ainda que ilusória e momentânea, da vida cotidiana, rotineira e insípida, e, por outra, de facilitar a acomodação a uma situação que, assim, se torna suportável (cf. ADORNO \& HORKHEIMER, 1985). De certo modo, a crítica da cultura, capitaneada pela Escola de Frankfurt, mas também pelos Estudos Culturais, aceitou as regras impostas à fantasia pelo capitalismo, confirmando-as por outra via; ambas as posições uniram-se nessa condenação a um fenômeno inerente à vida humana.

Nem todos, contudo, compartilham o preconceito, a começar por Sigmund Freud, talvez o principal responsável pelo resgate da fantasia e pelo esclarecimento de sua articulação às atividades artísticas de criação. Freud indica que a fantasia é motivada por desejos insatisfeitos; ela acolhe-os e elabora-os, buscando satisfazê-los por intermédio de processos como o sonho, a imaginação, o devaneio.

O escritor, por exemplo, canaliza esses desejos para sua obra criativa; essa, em certo sentido, permite-lhe externar lembranças insatisfatórias do passado, aliadas a experiências presentes, e, de algum modo, resolvê-las ou superá-las. Sob esse aspecto, a criação artística assemelha-se ao sonho do adulto ou ao brinquedo da criança, pois, durante sua ocorrência, evidenciam-se os proble- 
mas que afetam o sujeito e as possibilidades de solução para eles. Não por acaso, acredita Freud, algumas línguas usam a mesma palavra para designar o ato de brincar (play, em inglês; spiel, em alemão) e o de produzir peças literárias ou teatrais (FREUD, 1976a; 1976b).

Alojada no coração dos problemas de um indivíduo, a fantasia não pode levar à evasão; nem as imagens que ela libera desligam-se do cotidiano ou da existência dos homens com os quais o artista convive. Seu relacionamento com o mundo encontra acolhida no imaginário, mas esse não é meramente receptivo: trabalha essas sugestões exteriores, associa-as a recordações do passado, articula-as aos insumos resultantes das informações armazenadas pelo sujeito.

O mais importante é que a fantasia dá forma compreensível àqueles fenômenos, transparecendo por meio de ações e figuras, relações entre elas, saídas para os problemas levantados. E porque a forma empregada é compreensível, pode ser adotada por outros indivíduos, que, assim, têm condições de entender suas próprias dificuldades, refletir sobre elas, buscar um caminho para seus dramas pessoais ou sociais.

A fantasia transfere essa forma para a literatura, e o leitor procura ali os elementos que expressam seu mundo interior. Pode ser que ele não opere como o escritor, que produz um texto literário ao elaborar de modo criativo seus processos internos; mas ele passa por situação similar, na medida em que o mundo criado agita seu imaginário e faz com que, de alguma maneira, esse se manifeste e transforme-se em linguagem. Eis por que leituras significativas confundem-se com nosso cotidiano, tornam-se lembranças perenes, explicam nossa própria vida.

Sendo assim, para ser valorizada, a fantasia não precisa recorrer a um pouco provável ângulo utilitário ou aplicado. Ela não é prática, embora tenha sido aproveitada pela indústria cultural como maneira de aplacar a insatisfação interior resultante da divisão do trabalho e da mecanização da existência na capitalista pós-moderna.

É, contudo, condição básica de relacionamento entre os homens, porque faculta a expressão de seus dramas e das soluções possíveis. A criação artística, nesse sentido, assume papel preponderante, porque, operando a partir das sugestões fornecidas pela fantasia, socializa formas que permitem a compreensão dos problemas; logo, configura-se também como ponto de partida para o conhecimento do real e a adoção de uma atitude liberadora. 
Regressiva na formação, pois remonta a lembranças de problemas, a fantasia é prospectiva na formulação; e a literatura, sua herdeira, recebe como legado sua tônica utópica, acenando para as possibilidades de transformação do mundo e encaminhamento de uma vida melhor para todos que dependem dela para conhecer o ambiente que os rodeia.

A educação compartilha com a fantasia e a literatura a perspectiva utópica a que essas apontam. Etimologicamente, educar é extrair, levar avante, conduzir para fora e para frente. Funda-se, pois, em um ideal, o de que é possível mudar a atitude individual e a configuração da sociedade por meio da ação humana. Porque ideal, esse objetivo é seguidamente criticado e até rejeitado. A dificuldade maior, porém, não reside aí, mas no fato de não se vir concretizando e de estar ameaçado de desaparecimento por obsoleto.

A dificuldade reside também na circunstância de que, de ideal, esse objetivo converteu-se em um sistema: educação deixou de consistir em um processo, presente em várias das atividades sociais e culturais, para se apresentar como instituição, com estrutura, organograma, agentes, calendário e orçamento. Originalmente tão fluida como a fantasia, hoje evidencia sua substância e onipresença; mas não pode negar sua incapacidade de preencher o ideal de que dependeu seu aparecimento e que legitima sua continuidade. Por que não funciona? Deve funcionar? Neste caso, como deveria funcionar?

Essas questões não são irrelevantes; da resposta a elas depende a recuperação da utopia que, um dia, validou a implantação e organização do ensino. A resposta a elas possibilita também articular a utopia da educação àquela que está na base da fantasia e da literatura e move a vida humana, por mais atribulada que esteja a sociedade.

\section{Considerações finais}

Um ensino da literatura que se fundamente na leitura e resulte em uma prática dialógica talvez seja tão utópico ou romântico quanto qualquer projeto que, hoje, se refira à educação no Brasil. O sucateamento da escola reduziu-a ao grau zero de que já se falou; logo, não diz respeito exclusivamente ao problema da leitura e da literatura. As propostas que se apresentam são simultaneamente caras e baratas, realizáveis a curto e a longo prazo, viáveis e complexas. Barato e 
rápido é trabalhar com o aluno, seja ele criança ou adulto, a partir de sua própria experiência de leitura, lidando com um universo previamente dominado, desde que o objetivo seja abrir novos horizontes de conhecimento; caro e demorado é preparar o professor para levar a cabo essa tarefa, pois também ele foi afetado pelo progressivo desmonte da escola brasileira.

Por outro lado, a concretização de uma utopia para a educação no País se faz necessária, com suas nuances temporais e a consciência de seus limites. Suas metas são reconhecíveis: reportam-se à emancipação dos indivíduos que participam do sistema de ensino, sejam professores ou alunos, porque o processo da aprendizagem é permanente e afeta a ambos. E, sendo essa pedagogia de índole emancipatória, não pode dissociar-se do processo de liberação das falas dos sujeitos visados por ela. Para chegar à realização desse objetivo, a literatura desempenha papel fundamental, e talvez até o lidere, como aconteceu nos seus inícios, quando a poesia da epopéia formava os cidadãos da pólis grega. Talvez até tenha condições de desencadeá-lo, fazendo-o sem comprometer sua história, nem desmentir sua identidade ou alterar sua função.

\section{Referências Bibliográficas}

ADORNO, Theodor W.; HORKHEIMER, Max. Dialética do esclarecimento. São Paulo: Jorge Zahar, 1985.

ANDRADE, Carlos Drummond de. Os ombros suportam o mundo. In: Poesia completa. Rio de Janeiro: Nova Aguilar, 2002.

EVEN-ZOHAR, Itamar. La literatura como bienes y como herramientas. In: VILLANUEVA, Dario; MONEGAL, Antonio; BOU, Enric (Org.). Sin fronteras: ensayos de literatura comparada em homenaje a Claudio Guillen. Madri: Castalia, 1999.

FREUD, Sigmund. Delírios e sonhos na Gradiva de Jensen. Rio de Janeiro: Imagem, 1976 .

FREUD, Sigmund. Escritores criativos e devaneios. Rio de Janeiro: Imagem, 1976b.

ISER, Wolfgang. The Fictive and the Imaginary. Charting Literary Anthropology. Baltimore and London: The Johns Hopkins University Press, 1993.

KENNEDY, George A. A New History of Classical Rhetoric. Princeton: Princeton University Press, 1994. 